DIW BERLIN

Discussion

Papers

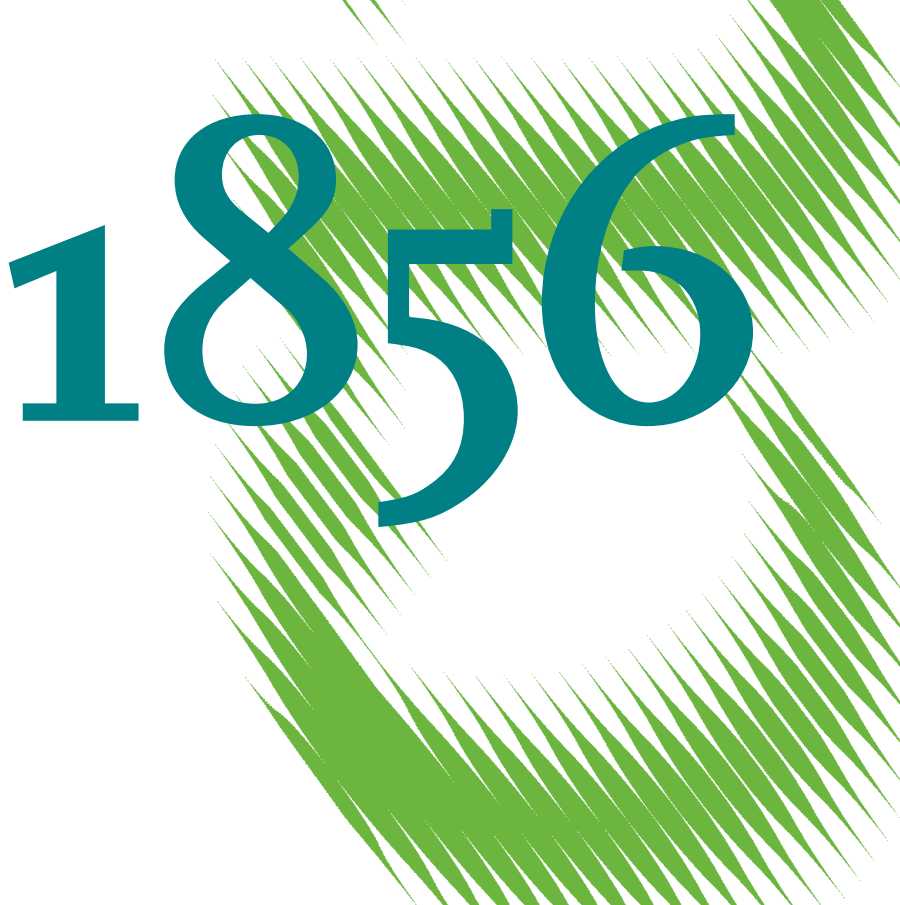

Technology Policy and Market Structure

Evidence from the Power Sector 
Opinions expressed in this paper are those of the author(s) and do not necessarily reflect views of the institute.

IMPRESSUM

(C) DIW Berlin, 2020

DIW Berlin

German Institute for Economic Research

Mohrenstr. 58

10117 Berlin

Tel. +49 (30) $89789-0$

Fax +49 (30) $89789-200$

http://www.diw.de

ISSN electronic edition 1619-4535

Papers can be downloaded free of charge from the DIW Berlin website:

http://www.diw.de/discussionpapers

Discussion Papers of DIW Berlin are indexed in RePEc and SSRN:

http://ideas.repec.org/s/diw/diwwpp.html

http://www.ssrn.com/link/DIW-Berlin-German-Inst-Econ-Res.html 


\title{
Technology Policy and Market Structure: Evidence from the Power Sector
}

\author{
Moritz Bohland Sebastian Schwenen*
}

March 31, 2020

\begin{abstract}
We show how policies to trigger clean technologies change price competition and market structure. We present evidence from electricity markets, where regulators have implemented different policies to subsidize clean energy. Building on a multi-unit auction model, we show that currently applied subsidy designs either foster or attenuate competition. Fixed, price-independent output subsidies decrease firms' mark-ups. In contrast, designs that subsidize clean output via a regulatory premium on the market price lead to higher mark-ups. We confirm this finding empirically using auction data from the Spanish power market. Our empirical results show that the design choice for technology subsidies significantly impacts pricing behavior of firms and policy costs for consumers.
\end{abstract}

Keywords: Subsidies, Clean Energy, Pricing, Electricity. JEL-Classification: D22, D44, D47.

*Bohland: Technical University of Munich, School of Management. Email: moritz.bohland@tum.de. Schwenen: Technical University of Munich, School of Management and German Institute for Economic Research (DIW Berlin), sebastian.schwenen@tum.de. We are grateful for helpful comments from Karsten Neuhoff, Pio Baake, Gregor Zöttl, Veronika Grimm, Karen Pittel, Chloé Le Coq, Jörn Richstein, Christian Traeger, Vadim Gorski, Anette Boom, Hanna Hottenrott, Michael Kurschilgen, José Pablo Chaves Ávila, Cristian Huse and from participants at the 2019 EARIE conference in Barcelona and workshop participants at the ifo Institute Munich and the University of Oldenburg. 


\section{Introduction}

Governments across the globe have implemented policies to limit climate change. Typically, these policies rely on pricing carbon, awarding R\&D grants, or subsidizing the deployment of "clean" technologies (e.g., Goulder et al., 1999; Acemoglu et al., 2012). While previous research has focused on the market impact of carbon prices and R\&D support (e.g., Johnstone et al., 2010; Fabra and Reguant, 2014; Aghion et al., 2016; Calel and Dechezlepretre, 2016), relatively less is known on how subsidies for clean technology change market outcomes and welfare. In this paper, we address this question by studying the impact of subsidies for clean energy on market outcomes in the power sector.

Targeted technology policy is omnipresent in power markets, where many governments have rolled out large-scale programs to subsidize renewable energy. ${ }^{1}$ To better understand the consequences of subsidies on competition and market structure, we contribute by offering a model of pricing behavior under different policy designs. By exploiting detailed firm-level data from the Spanish power market, we also investigate welfare effects empirically and find that support mechanisms can affect market prices, rents, and as such overall policy costs.

Our model formalizes pricing decisions by firms that produce with "clean", i.e., lowcarbon and "dirty" carbon-intensive inputs. The regulator implements a mechanism that establishes an output subsidy for the clean technology. Motivated by existing real-world mechanisms in electricity markets, we investigate two standard designs to reward this subsidy. These two mechanisms are common and, in 2017, were employed by more than 80 countries worldwide (Murdock et al., 2018). First, subsidies may come as a linear tariff per unit produced from clean assets. Alternatively, subsidies are often implemented via a regulatory premium that clean production earns on top of the market price. In the former mechanism ("tariff"), clean production is rewarded independently of the market price and yields profits equal to its output times the per-unit subsidy. In essence, this mechanism constitutes a forward contract for producing with clean technologies between producers and the regulator. ${ }^{2}$ In the alternative mechanism ("premium"), profits from clean production depend on the equilibrium market price and are topped up by the regulatory premium. Our model investigates pricing behavior under these two regimes and allows for both perfect and imperfect competition.

\footnotetext{
${ }^{1}$ Next to the power sector, technology-specific subsidies are increasingly used to support low-emission vehicles in the automobile market (e.g., Huse and Lucinda, 2013; Adamou et al., 2014; Gulati et al., 2017).

${ }^{2}$ Also the contracts for differences currently applied in the UK represent schemes that rely on fixing output prices. For a more detailed taxonomy of subsidy mechanisms see Batlle et al. (2012).
} 
We find that under perfect competition, the design of the support mechanism is irrelevant. However, when firms are able to charge mark-ups, the design of the support mechanism changes market prices and rents. In particular, our results highlight the critical role of market size effects on pricing incentives. Fixed per-unit tariffs decrease market size, as only conventional, carbon-intensive capacity is sold on the market. Consequently, firms that own conventional capacity only face demand left unsatisfied from clean production. When firms charge strategic mark-ups, they hence face a smaller market, resulting in lower equilibrium market prices. In contrast, when the support mechanism rewards clean production by a premium on top of the market price, the market size remains large. In this case, profits for both clean and conventional technologies are a function of the equilibrium market price, and firms have ample incentives for charging higher mark-ups.

We empirically test this prediction on pricing and mark-up strategies under different support designs. Next to detailed bidding data from Spanish electricity wholesale auctions, we exploit an institutional change in the support design. In Spain, both the tariff mechanism and the premium mechanism have been applied, where the latter successively replaced the former (Batlle et al., 2012). We conjecture that, following the transition to the premium mechanism, we observe higher equilibrium mark-ups and thus market prices.

We investigate this effect using hourly observations on price-quantity decisions by Spanish power producers. Our empirical findings show that the mark-up significantly increases under the premium mechanism as compared to the tariff mechanism. The magnitude of this effect is economically significant. Counterfactual calculations show that during our period of observation the premium-based design redistributes rents to producers that accumulate to $3 \%$ of market revenue, hence increasing the overall policy costs for consumers.

We also document this effect when focusing on the two largest firms in the market. Especially larger firms with high shares of clean production increase their mark-ups. In addition, we illustrate how the policy change impacts market concentration. Specifically, we show that mark-ups increase despite a decrease in market concentration. As such, we find that measuring the competitive benefits of different support designs by market concentration indicators can be misleading.

Our paper contributes to the vast literature on policy designs to control and limit climate change. One strand within this literature has focused on carbon pricing and its effect on electricity prices (e.g., Fabra and Reguant, 2014), as well as its effect on investment incentives for clean technologies (e.g., Calel and Dechezlepretre, 2016). A second strand, to which we more closely relate, examines targeted subsidies for clean energy. Reguant (2019) investi- 
gates the interaction between carbon taxes, feed-in tariffs, and renewable portfolio standards in California, and shows trade-offs between efficiency and distributional concerns. Dressler (2016), Acemoglu et al. (2017), and von der Fehr and Ropenus (2017) analyze the market impact of support mechanisms and costs to consumers theoretically. They propose oligopoly or dominant firm models to analyze pricing decisions when firms hold a portfolio of conventional and subsidized wind and solar capacity. Focusing on the Texas power market, Cullen (2013) evaluates both costs and benefits of renewable support and estimates that the value of emission offsets from wind power outweighed its subsidies. Furthermore, Gowrisankaran et al. (2016) develop a method to quantify the economic value of large-scale solar energy and apply their method to the Arizona power market, highlighting the social costs of intermittent renewable production. Indeed, while the literature has thus far mostly evaluated the costs and benefits of subsidy mechanisms, their optimal design and consequences for firms' pricing decisions have not been empirically documented yet.

Furthermore, our paper adds to the literature in industrial economics on strategic pricing in multi-unit auctions for electricity (e.g., Green and Newbery, 1992; von der Fehr and Harbord, 1993; Wolfram, 1998; Fabra et al., 2006; Reguant, 2014). More specifically, our model draws from the share auction framework in Wilson (1979) and multi-unit auction models that explore bidding strategies in power markets (e.g., Hortaçsu and Puller, 2008). We rely on this modeling approach as it aids us in tailoring our model to renewable energy in power markets. We amend the model by adding different support mechanisms for clean generation. The mechanism through which our model demonstrates the effect of subsidies on equilibrium market prices is similar to the one outlined in the literature on forward markets (e.g., Allaz and Vila, 1993; Wolak, 2003a; Bushnell et al., 2008; Van Koten and Ortmann, 2013; Eijkel et al., 2016; Ito and Reguant, 2016). Equivalent to forward contracts, clean generation that is rewarded by a fixed tariff reduces spot demand and thus prices. With a premium, this effect vanishes and prices increase.

The remainder of this article is organized as follows. Section two presents the regulatory environment and data. Section three outlines a model of bidding behavior in multi-unit auctions in electricity markets. The model incorporates the two standard mechanisms of technology support and closely guides our empirical investigation. In section three, we illustrate our empirical strategy and discuss different econometric specifications. Section four presents our empirical findings. Section five concludes. 


\section{Regulatory environment, market places, and data}

We investigate technology support for clean energy by studying the Spanish electricity market. We focus on the Spanish market to exploit a regulatory change in the support mechanism introduced in 2004. Furthermore, this market allows us to utilize detailed firm-level data from wholesale auctions. During our period of observation, from January 2004 to December 2005, clean energy in the Spanish power market mainly came from wind power, but also included small-scale hydro resources, bio-energy, and small combined heat and power plants. ${ }^{3}$ In contrast, conventional carbon-intensive technologies comprise thermal power plants that use natural gas, coal, or fuel oil as input.

\subsection{Market and regulatory environment}

During the years 2004 and 2005, the Spanish power market exhibited an oligopolistic market structure. The market was dominated by four large power producers: Endesa, Iberdrola, Union Fenosa, and Hidrocantábrico, who jointly covered about $80 \%$ of the market. Endesa and Iberdrola alone supplied about $50 \%$ of sales to the market.

The electricity mix was largely dominated by thermal power plants. Coal power plants contributed most (more than 25 percent), followed by nuclear power stations and combined cycle gas turbines. ${ }^{4}$ Spain, however, was an early adopter of renewable power, especially with regard to onshore wind. The installed base of onshore wind power amounted to about 10 gigawatt $(\mathrm{GW})$ at the end of our observation period. For comparison, daily peak demand during our observation period varied around $26 \mathrm{GW}$.

In March 2004, new regulations introduced by the Royal Decree 436 entered into force. After the regulation became binding, substantial quantities of electricity from renewable plants successively entered the spot market. The regulation permitted power producers to choose between a fixed tariff and a market based remuneration, where the latter included a regulatory premium on top of the market price for production from renewable sources. The fixed tariff in effect constituted a contract between the government and renewable producers. In contrast, under the premium mechanism renewable output was sold in the electricity spot market. This is, renewable power had to be marketed as any other type of power generation, but received a top-up on the equilibrium market price. In terms of magnitude, the tariff

\footnotetext{
${ }^{3}$ Small scale hydro refers to units with capacity less than $50 \mathrm{MW}$. Waste incineration and small cogeneration plants are also subsidized. Our results are robust to excluding CHP plants and waste incineration, hence are largely driven by wind power.

${ }^{4}$ Information are from the Spanish market operator OMIE (Operador del Mercado Ibérico de Energía).
} 
was set at about $6.50 € / \mathrm{MWh}$, while the premium plus average market prices yielded about $7.10 € / \mathrm{MWh}^{5}$

Although the expected revenue of selling electricity in the market and receiving the additional premium exceeded the expected revenue of the tariff, not all producers changed to the premium scheme immediately. The transition took place continuously rather than instantaneously. Upon choosing to switch to a market based remuneration plus premium, producers were set to stay within this mechanism for at least one year. This commitment and potential risk aversion of smaller agents may in parts explain the continuous transition. Figure A.1 in the Appendix plots the evolution of clean output sold in the tariff and in the premium mechanism.

\subsection{The day-ahead market}

Our empirical analysis investigates pricing and mark-up strategies on the day-ahead electricity market, as it represents the by far most liquid electricity market in Spain and covers about 70 percent of produced electricity in 2004 and 2005. ${ }^{6}$ The day-ahead electricity market clears as a multi-unit uniform price auction, where producers and retailers participate. Subsequent to the day-ahead market, participants may balance their positions on an intraday market, which during our period of observation however constituted a much smaller market in terms of volume. The market for forward contracts was negligible during our observation period (Vázquez et al., 2006). ${ }^{7}$ Producers mostly hedged via vertically integrating their retail business. Indeed, Crampes and Fabra (2005) report that the large producing companies also held significant stakes in the retail sector. Below, we therefore address vertical integration in our empirical specification by controlling for a firm's subsidiary retail demand in the day-ahead market.

The day-ahead market is organized by the Spanish market operator OMIE. Generators and retailers are placing bids for each hour of the consecutive day. In contrast to many other EU markets and in line with most US markets, supply bids have to be submitted at the plant-level, instead of covering a firm's portfolio of production units. For each power plant, generators can place up to 25 distinct supply bids, specifying different prices and quantities. The market operator gathers and sorts supply (demand) bids in increasing (decreasing) order

\footnotetext{
${ }^{5}$ Numbers refer to subsidy levels for onshore wind power in 2004 following Del Río and Gual (2007) and del Río González (2008).

${ }^{6}$ About 84 percent of electricity was traded in centralized spot markets (day-ahead and intraday). The remaining sales mainly include generation subject to the tariff, and to a lesser extent bilateral trades.

${ }^{7}$ Also the EU DG Competition energy sector inquiry (SEC(2006)1724, 10 January 2007, Part II) finds that forward markets were insignificant.
} 
and clears the market. Hourly prices and quantities are determined in uniform price auctions, i.e., all production units with bids below the clearing price receive the latter.

All units are obligated to place bids for their entire available capacity. Power generators participating in the market are allowed to place both simple and complex bids. Whereas simple bids signal the willingness to sell a certain amount of electricity at or above the price bid, complex bids add constraints on the minimum daily revenue required by a plant. Firms make use of complex bids, for instance, whenever plants face additional costs to start-up. ${ }^{8}$ If operating margins throughout a day do not cover a plant's revenue requirement, all bids by this plant are excluded from the auction. Complex bids thus change the probability of winning and being dispatched for the respective plants (Reguant, 2014). Lastly, there exists a price cap of $180.30 € / \mathrm{MWh}$, which was however never binding during our observation period. Indeed, clearing prices ranged between $3 € / \mathrm{MWh}$ and $127 € / \mathrm{MWh}$.

\subsection{Data}

To study the effects of subsidies on pricing behavior, we require data on firms' mark-ups, that is, their supply bids and marginal costs, as well as data on demand and actual sales. We therefore collect all market participants' supply and demand bids on the day-ahead market, the type of technology for which a supply bid was submitted, the equilibrium clearing price and resulting sales for each firm. The data come, as market clearing does, in hourly granularity. In detail, our main dataset consists of all hourly supply bids for each plant and each company for the years 2004 and 2005. As we are interested in the pricing decisions by the dominant producers, we restrict our sample to bids submitted by the four largest companies, which cover about $80 \%$ of the market. For all fringe firms, we keep the data on their joint output. The fringe consists mostly of small renewable producers. Last, we use fuel price data and EU ETS prices from Bloomberg and Thomson Reuters to estimate plant-specific marginal cost of power production. We use engineering estimates to attach the efficiency to each thermal power plant in the sample. Appendix B illustrates our data in more detail. In sum, the data allow us to study firm-specific sales for clean and conventional generation, as well as the firms' pricing strategies in the wholesale market.

\footnotetext{
${ }^{8}$ Doraszelski et al. (2018) study related mechanisms that remunerate wear and tear costs for ramping up and down power plants in the UK electricity market.
} 


\section{Model and empirical strategy}

To formalize firms' pricing decisions, we employ a model of bidding behavior in multi-unit uniform price auctions, which constitute the standard clearing mechanism in electricity markets. The literature on multi-unit auctions considers continuous bid functions (e.g., Wilson, 1979; Klemperer and Meyer, 1989; Hortaçsu and Puller, 2008; Holmberg and Newbery, 2010) and discrete bidding strategies (e.g., Fabra et al., 2006; Kastl, 2006, 2012). Both modeling approaches have been applied to electricity markets. Wolfram (1998), Fabra et al. (2006), Reguant (2014), and Schwenen (2015) study discrete bids, while Green and Newbery (1992), Wolak (2000), and Hortaçsu and Puller (2008) study price games with continuous supply functions. Our model follows the framework in Hortaçsu and Puller (2008) as it aids us in formally incorporating stochastic wind and solar output into our analysis. ${ }^{9}$

\subsection{A model for strategic pricing with technology support}

We model strategic firms who decide on their supply to the market at any possible market price $p$. Each firm $i$ therefore chooses its supply function $S_{i}(p)$, where supply may stem from "clean" renewable production (wind and solar) or from emitting conventional production. We denote firm $i$ 's clean production as $x_{i}^{c}$ and model its output as random variable, whose realization is private information to firm $i$. At the time of submitting bids, firm $i$ knows its own renewable output, but not the one of its rivals. As the supply of firm $i$ hence depends on its realized renewable output, we on occasion write $S_{i}(p)=S_{i}\left(p, x_{i}^{c}\right)$. Last, we assume that firms are capacity constrained in their clean output so that $S_{i}(p)>x_{i}^{c}$ at any equilibrium market price. ${ }^{10}$

The regulator implements a set of support mechanisms for firm $i$ 's clean production. Specifically, the regulator offers two types of support mechanisms: In the first mechanism, the firm receives a fixed tariff $t$ for every unit produced from clean assets. In the alternative mechanism, the firm opts for a premium on top of the market price for its clean supply. This premium is denoted by $s$.

To incorporate both mechanisms into our model, we allow firms to have a share $\alpha_{i}$ of their

\footnotetext{
${ }^{9}$ In models with discrete bids, a large domain of supply or demand shocks can lead to mixed strategies if bids are long-lived and used for several rounds of market clearing (Fabra et al., 2006). Kastl (2012), Holmberg et al. (2013), and Anderson and Holmberg (2018) show conditions under which the difference in discrete and continuous models is qualitatively negligible. Fabra and Llobet (2019) provide a model with discrete bids and uncertain renewable output.

${ }^{10}$ Otherwise, there would be little need for subsidies. We also show that in our empirical setting, firms always produce output larger than their renewable capacity.
} 
clean production subsidized by the premium, while they receive the tariff for the remaining share, $1-\alpha_{i}$. This modeling approach matches our empirical application and many realworld mechanisms, where firms can decide on their preferred form of subsidy over a specified period of time. Firms decide on their share $\alpha_{i}$ in advance of participating in the market, so that the choice on the support mechanism is sunk when firms submit their supply function.

We model demand to be deterministic and denote demand as a function of price by $D(p) .{ }^{11}$ When $N$ firms participate in the market, the clearing price $p^{*}$ must satisfy

$$
\sum_{i}^{N} S_{i}\left(p^{*}, x_{i}^{c}\right)=D\left(p^{*}\right)
$$

Ex-post of market clearing, each firm's profits yield

$$
\pi_{i}=S_{i}\left(p^{*}\right) p^{*}-C_{i}\left(S_{i}\left(p^{*}\right)\right)+s \alpha_{i} x_{i}^{c}+\left(t-p^{*}\right)\left(1-\alpha_{i}\right) x_{i}^{c}
$$

where $C_{i}$ is the firm's cost function. The first two terms capture standard revenue and cost considerations. The third term represents the premium on top of the market price that firm $i$ receives for its share $\alpha_{i}$ of clean energy sold at the respective market price. The last term adds firm $i$ 's profits for its remaining share of renewable output for which the firm receives the fixed tariff.

Note that firm $i$ faces uncertainty on the clearing price due to the unknown clean production of its competitors. Put differently, the market price depends on the realization of the aggregate clean output of firm $i$ 's rivals, and how this output changes their supply function. To capture this uncertainty in firm $i$ 's pricing, we follow Wilson (1979) and Hortaçsu and Puller (2008) and map randomness in rival supply to randomness in price. Denoting the cumulative distribution function of the market clearing price, given firm $i$ 's supply at this price, as $H_{i}\left(p, S_{i}\right) \equiv \operatorname{Pr}\left(p^{*}<p \mid S_{i}\right)$, the maximization problem can be written as

$$
\max _{S_{i}(p)} \mathbb{E}\left[\pi_{i}\right]=\int_{\underline{p}}^{\bar{p}}\left[S_{i}(p) p-C_{i}\left(S_{i}(p)\right)+s \alpha_{i} x_{i}^{c}+(t-p)\left(1-\alpha_{i}\right) x_{i}^{c}\right] d H_{i}\left(p \mid S_{i}\right) .
$$

Using calculus of variations, the Euler-Lagrange first-order condition yields

$$
p-C_{i}^{\prime}\left(S_{i}^{*}(p)\right)=\left(S_{i}^{*}(p)-\left(1-\alpha_{i}\right) x_{i}^{c}\right) \frac{H_{S}\left(p, S^{*}(p)\right)}{H_{p}\left(p, S^{*}(p)\right)}
$$

\footnotetext{
${ }^{11}$ Demand may be stochastic. Our results are independent of this modeling choice and we therefore stick to deterministic demand.
} 
where $S_{i}^{*}(p)$ is firm $i$ 's optimal supply function, $C_{i}^{\prime}$ marginal costs, and $H_{S}$ and $H_{p}$ are derivatives with respect to supply and price, respectively. The left hand side represents the firm's mark-up at its level of supply $S_{i}^{*}(p)$. The right hand side shows that the markup depends on overall output and the amount of clean production supported by the tariff. Appendix A presents more details on the derivation of the optimality condition.

To interpret the optimality condition, note that $H_{p}$ is the probability density function of price and must be positive. Also $H_{S}$ must be positive because additional supply increases the likelihood that price is below any given value. Vice versa, withholding supply decreases the likelihood that the equilibrium price is below a certain value. The right hand side consequently is positive and determines a non-zero mark-up, unless the supply effect of firm $i$ on the price distribution is infinitely small. ${ }^{12}$

In addition, the optimality condition shows that all clean output rewarded by the tariff, $\left(1-\alpha_{i}\right) x_{i}^{c}$, decreases the mark-up. Note that this effect is conditional on a firm indeed having the ability to impact the market price distribution. As this probability approaches zero, also the effect of inframarginal capacity on the mark-up vanishes.

The effect of the tariff mechanism on price is similar to the price-reducing effect of forward contracts as first suggested by Allaz and Vila (1993) and as documented in Wolak (2003a), Bushnell et al. (2008), and Hortaçsu and Puller (2008). The two cases are similar because both, capacity sold at forward prices and clean production sold via the tariff, reduce a firm's residual demand. As a result of declining residual demand, the equilibrium mark-up must decrease accordingly.

To compute equation (4), one needs to either derive or estimate $H_{S}$ and $H_{p}$. As Hortaçsu and Puller (2008) show, the analytical derivation simplifies when restricting the strategies to be additively separable. In our context, this assumption translates into renewable shocks that shift supply curves in a parallel fashion. We therefore consider strategies where clean and emitting supply is additive, this is, $S_{i}\left(p, x_{i}^{c}\right)=S_{i}\left(p, x_{i}^{c}\right)+\varepsilon\left(x_{i}^{c}\right)$, where the function $\varepsilon$ translates realized renewable output into parallel shifts. ${ }^{13}$

As shown in Appendix A, restricting strategies to be additive allows to derive $\frac{H_{S}}{H_{p}}$ analyt-

\footnotetext{
${ }^{12}$ As discussed in Wolak (2003b) and Hortaçsu and Puller (2008), the strategies that follow equation (4) are also ex-post optimal, as long as shocks to supply or demand are additive.

${ }^{13}$ Note that this supply function still allows for mark-ups on renewable supply. We just restrict the uncertainty to be additive. For example, supply could be linearly upward sloping with positive mark-ups over the entire output range, where $\varepsilon$ shifts the lowest price with positive output. In Hortaçsu and Puller (2008), parallel shifts are instead introduced by forward contracts with volume unknown to firm $i$ 's competitors. In our setting, the additive separability assumption captures that renewable shocks in electricity markets typically shift the entire supply curve.
} 
ically with $\frac{H_{S}}{H_{p}}=\frac{1}{m_{i}(p)}$, where $m_{i}(p)$ denotes, in absolute terms, the slope of firm $i$ 's residual demand at price $p$. Furthermore, recalling that we study a setting where firms are capacity constrained and sell all of their subsidized output, we can rewrite $S_{i}^{*}(p)=x_{i}^{e}(p)+x_{i}^{c}$, where $x_{i}^{e}(p)$ is the emitting part of firm $i$ 's supply curve. The optimal strategy in equation (4) hence simplifies to

$$
p-C^{\prime}\left(S_{i}^{*}(p)\right)=\left(\alpha_{i} x_{i}^{c}+x_{i}^{e}(p)\right) \frac{1}{m_{i}(p)} .
$$

Given that price, marginal costs, demand, as well as clean and conventional production are observable, the optimality condition is also estimable. Equation (5) states that clean supply under the premium mechanism contributes positively to a firm's mark-up. This is because, under the premium mechanism, the equilibrium market price applies to both clean and conventional output. ${ }^{14}$ Therefore, while the premium itself is not relevant for optimal pricing, the remuneration of clean supply under the premium regime nonetheless depends on the market price and as such impacts a firm's pricing decision. We summarize this finding, that we test in our empirical application, in the following proposition.

Proposition 1 The optimal mark-up of firm $i$ depends positively on firm $i$ 's share of clean output sold under the premium mechanism, i.e., the mark-up increases in $\alpha_{i} x_{i}^{c}$.

\subsection{Empirical strategy}

Our empirical strategy closely relies on Proposition 1 and the optimality condition in equation (5). Following Proposition 1, we are interested in evaluating price effects of the premium mechanism. To estimate the price effects of marketed renewable production $\alpha_{i} x_{i}^{c}$, we test the optimality condition at the margin, this is, for all mark-ups at the clearing price $p^{*}$ and submitted quantities $S_{i}\left(p^{*}\right)$. More specifically, we test Proposition 1 by log-linearizing the optimality condition at the margin to

$$
\ln \left(p^{*}-C_{i}^{\prime}\left(S_{i}\left(p^{*}\right)\right)\right)=\ln \left(\alpha_{i} x_{i}^{c}+x_{i}^{e}\left(p^{*}\right)\right)-\ln m_{i}\left(p^{*}\right)
$$

Furthermore, rearranging $\alpha_{i} x_{i}^{c}+x_{i}^{e}\left(p^{*}\right)$ to $\left(1+\theta_{i}\right) x_{i}^{e}\left(p^{*}\right)$ with $\theta_{i}=\frac{\alpha_{i} x_{i}^{c}}{x_{i}^{e}\left(p^{*}\right)}$ yields a specification that allows to estimate the model as:

$$
\ln \left(p^{*}-C_{i}^{\prime}\left(S_{i}\left(p^{*}\right)\right)\right)=\ln \left(1+\theta_{i}\right)+\ln x_{i}^{e}\left(p^{*}\right)-\ln m_{i}\left(p^{*}\right) .
$$

\footnotetext{
${ }^{14}$ The result that mark-ups increase in offered quantity is in line with a range of specifications for standard oligopoly and multi-unit auction models (e.g., Klemperer and Meyer, 1989). Note that firms can sell this additional output because demand in the spot market increases by the same amount by which renewable sales in the tariff mechanism are reduced.
} 
Equation (7) states that, at the margin, the mark-up is a function of all of firm i's conventional capacity and the ratio of its marketed clean over conventional capacity, as well as the slope of firm i's residual demand. The slope of residual demand affects the mark-up negatively, where for a more elastic residual demand (higher $m_{i}$ ), the mark-up decreases.

To capture price effects of subsidized renewable sales over time, we estimate equation (7) by pooling data across auctions, controlling for observed and unobserved factors that may vary from one auction to the next. In detail, we add hourly time indeces to equation (7) and estimate:

$$
\ln \left(p_{i t}^{*}-C_{i t}^{\prime}\left(S_{i t}\left(p^{*}\right)\right)\right)=\beta_{0}+\beta_{1} \ln \left(1+\theta_{i t}\right)+\beta_{2} \ln x_{i t}^{e}\left(p^{*}\right)+\beta_{3} \ln m_{i t}\left(p^{*}\right)+\gamma W+\epsilon_{i t},
$$

where the matrix $W$ comprises different time fixed effects and, depending on the specification, plant and company fixed effects. Time fixed effects capture regularly reoccurring patterns in power markets, such as demand or temperature. We include hour, day-of-week, month, and year fixed effects that capture hourly, daily, and seasonal demand patterns as well as other time-specific heterogeneity. To the extent that unobserved production cost occur on hourly or daily patterns, fixed effects also capture higher mark-ups due to regularly emerging ramping or start-up costs.

To interpret the absolute effect of sales from clean energy, we also deviate from the model and estimate a version that estimates the elasticity between marketed clean production and the mark-up more directly:

$$
\ln \left(p_{i t}^{*}-C_{i t}^{\prime}\left(S_{i t}\left(p^{*}\right)\right)\right)=\beta_{0}+\beta_{1} \ln \alpha_{i} x_{i t}^{c}+\beta_{2} \ln x_{i t}^{e}\left(p^{*}\right)+\beta_{3} \ln m_{i t}\left(p^{*}\right)+\gamma W+\epsilon_{i t} .
$$

Our data allow to compute all required variables. First, we can compute the hourly mark-up on marginal costs, defined as the price-bid submitted at the quantity $S_{i}\left(p^{*}\right)$ by firm $i$ in auction $t$ minus marginal costs of the respective plant. Second, the renewable output marketed under the premium mechanism, $\alpha_{i t} x_{i t}^{c}$, as well as the amount of conventional production $x_{i t}^{e}\left(p^{*}\right)$ are directly observable in the data. Note that our data on marketed renewable production captures clean inframarginal capacity under the premium scheme $\alpha_{i} x_{c}$, rather than merely $\alpha_{i}$. Next to improved interpretability, this is because we do not observe the share $\alpha_{i}$ of renewables under the premium mechanism, at least not at firm-level. Instead, we observe the amount of renewables directly sold in the market and hence earning the premium. For running our first specification, we in addition compute the share of marketed renewable energy, $1+\theta_{i t}$. Last, we use the data on demand bids to compute the slope of the 
residual demand around the clearing price. ${ }^{15}$ Table 1 presents the summary statistics.

Table 1: Summary statistics

\begin{tabular}{lrrrrrr}
\hline \hline & Mean & Median & Std. dev. & Min & Max & Obs. \\
\hline Clearing prices [€/MWh] & 40.1 & 37.8 & 18.4 & 10.1 & 127.0 & 14,101 \\
Marginal costs at $S_{i}\left(p^{*}\right)[€ / \mathrm{MWh}]$ & 18.9 & 16.2 & 9.3 & 8.9 & 87.9 & 30,390 \\
Mark-up [€/MWh] & 17.0 & 14.4 & 13.2 & 0.0 & 101.6 & 30,390 \\
Renewable generation [MW] & 102.4 & 5.9 & 223.0 & 0.0 & 2108.5 & 30,390 \\
Conventional generation [MW] & 4622.4 & 3617.2 & 3033.7 & 745.6 & $13,064.5$ & 30,390 \\
\hline \hline
\end{tabular}

Notes: Sample from January 2004 to December 2005. Observations are hourly and comprise the largest four firms in the market. Hours where pumped storage, hydro power plants, imports, or nuclear power produced at the margin are excluded, as their marginal production costs are prone to measurement bias.

Note that firms submit discrete bid functions. Therefore, the mark-up $p_{i t}^{*}-C_{i t}^{\prime}\left(S_{i t}\left(p^{*}\right)\right)$ may not be defined, if a firm's residual demand intersects its supply function in between steps. Indeed, in most hours there is only one of the four dominant firms that submits a bid that is identical to the clearing price. To compute the mark-up for all four firms, we therefore use each firms price-bid at its equilibrium quantity $S_{i}\left(p^{*}\right)$, which may be equal to or lower than $p^{*}$. Our results are robust to computing the mark-up using the unique clearing price for all firms instead of their marginal bid. ${ }^{16}$

Our empirical approach derives from the modeled optimality condition and hence is subject to the underlying model assumptions. First, we do not model forward contracts. However, firms may change their forward market strategy in response to selling renewable generation under the premium mechanism, as they are exposed to price volatility for a larger volume of sales. Yet, since forward contracts during our period of observation have been negligible, we conjecture that forward market reactions have not been significant. In addition, price exposure is limited by the relatively stringent price cap in Spain on the dayahead and intraday market. If, however, hedging incentives and forward volumes were to increase in response to additional price exposure for renewable output, our model estimates are likely to be downward biased, as a simultaneous increase in forward sales would negatively effect spot market prices (e.g., Wolak, 2000; Bushnell et al., 2008).

\footnotetext{
${ }^{15}$ We present our approach to construct the slope of residual demand in Appendix B.

${ }^{16}$ To investigate the distance between the clearing price and a firm's price-bid at $S_{i}\left(p^{*}\right)$, we calculated a distance ratio defined as $\frac{p^{*}-\text { bid }}{p^{*}}$. The median difference between the clearing price and a firm's bid is below $3 \%$. We therefore conjecture that modeling smooth supply functions, at least at the margin, depicts the firms' pricing strategies reasonably well.
} 
Lastly, our findings rely on the presumption that mark-ups increase because firms account for inframarginal renewable sales in their optimal pricing decision. Whereas this is in line with standard oligopoly models where mark-ups increase in output, in our application high mark-ups could, in turn, lead to more companies switching to the premium mechanism. Yet, we view this possibility as not realistic as the premium mechanism has been the dominant mechanism by design. In fact, from the start the premium mechanism has been constructed to yield more revenue as compared to the tariff mechanism (del Río González, 2008). Below, we also rule out that mark-ups could have been increasing as a result of changes in market concentration. On the contrary, we find that the HHI falls during our observation period.

\section{Results}

Table 2 presents the results of our empirical analysis and shows the estimated coefficients for our two main specifications. The first two columns report estimates when using the share, $1+\theta_{i t}$, to measure the impact of marketed renewable generation on the mark-up. The estimates for the share of renewable output are positive and robust in magnitude. Also the coefficients of conventional capacity and for the slope of residual demand show signs as conjectured.

In column two, we in addition control for a company's degree of vertical integration. Similar to the well-studied effect of forward contracts, we expect that a high share of subsidiary retail firms on the demand side attenuates incentives to submit high bids. To construct this control, we first sum up the aggregate quantity of satisfied demand from retailers owned by the corresponding generating companies. As control variable, we then use the sum of a firm's "own" demand relative to total demand satisfied in the respective hour. As shown in column two, the estimates suggest that indeed firms submit lower bids if a larger portion of the market demand stems from their own retail firms.

In specifications three and four, we then use the absolute amount of subsidized renewable generation. While the estimated effects of conventional capacity and demand elasticity stay robust, the direct elasticity of renewable generation on the mark-up is now estimated to be about $0.05 \%$. This effect is again significant and robust also when controlling for the demand of subsidiary retailers in specification four.

Applying our estimate of 0.046 percent for the mark-up effect of renewable energy on the mean renewable generation and the mean power price during the last month of our sample, we find that the implementation of the premium scheme yields an overall price increase of 
about $1.80 € /$ MWh, raising the average market price by about 3 percent. $^{17}$

Table 2: Mark-up Regressions.

\begin{tabular}{|c|c|c|c|c|}
\hline & (1) & $(2)$ & $(3)$ & (4) \\
\hline $\begin{array}{l}\text { Renewable output } \\
\qquad \ln \left(1+\theta_{i}\right)\end{array}$ & $\begin{array}{c}1.519 \\
(17.98)\end{array}$ & $\begin{array}{c}1.416 \\
(16.91)\end{array}$ & & \\
\hline $\ln \alpha_{i} x_{i}^{c}$ & & & $\begin{array}{c}0.046 \\
(15.07)\end{array}$ & $\begin{array}{c}0.044 \\
(15.71)\end{array}$ \\
\hline $\begin{array}{l}\text { Conventional output } \\
\ln x_{i}^{e}\left(p^{*}\right)\end{array}$ & $\begin{array}{c}0.442 \\
(20.92)\end{array}$ & $\begin{array}{c}0.500 \\
(24.01)\end{array}$ & $\begin{array}{c}0.471 \\
(21.95)\end{array}$ & $\begin{array}{c}0.529 \\
(25.00)\end{array}$ \\
\hline $\begin{array}{l}\text { Demand slope } \\
\ln m^{*}\end{array}$ & $\begin{array}{l}-0.035 \\
(-10.02)\end{array}$ & $\begin{array}{l}-0.033 \\
(-9.35)\end{array}$ & $\begin{array}{l}-0.039 \\
(-11.29)\end{array}$ & $\begin{array}{l}-0.037 \\
(-10.51)\end{array}$ \\
\hline $\begin{array}{l}\text { Own retail demand } \\
\text { ln (retail demand over total })\end{array}$ & & $\begin{array}{l}-0.506 \\
(-15.45)\end{array}$ & & $\begin{array}{l}-0.516 \\
(-15.77)\end{array}$ \\
\hline Plant fixed effects & Yes & Yes & Yes & Yes \\
\hline Company fixed effects & Yes & Yes & Yes & Yes \\
\hline Observations & 30,390 & 30,390 & 30,390 & 30,390 \\
\hline $\mathrm{R}^{2}$ & 0.69 & 0.70 & 0.69 & 0.70 \\
\hline
\end{tabular}

Notes: Dependant variable is the mark-up by firm $i$ in auction $t$. Specifications (1) and (2) use a firm's share of renewable to conventional output, $\ln \left(1+\theta_{i}\right)$, as explanatory variable. Specifications (3) and (4) use a firm's amount of marketed renewable output, $\ln \alpha_{i} x_{i}^{c}$. Sample runs from January 2004 to December 2005. T-statistics are in parentheses. All regressions include hour, weekday, month, and year fixed effects. Standard errors are clustered at the auction-level.

\footnotetext{
${ }^{17}$ Note that for specifications three and four, theory does not require the estimates for renewable and conventional generation to be equal. This is because small changes in $\ln \left(\alpha_{i} x_{i}^{c}+x_{i}^{e}\left(p^{*}\right)\right)$ in equation (6) can be approximated as $\delta \ln \left(\alpha_{i} x_{i}^{c}+x_{i}^{e}\left(p^{*}\right)\right) \approx \delta \ln \left(\alpha_{i} x_{i}^{c}\right) \frac{\alpha_{i} x_{i}^{c}}{\alpha_{i} x_{i}^{c}+x_{i}^{e}\left(p^{*}\right)}+\delta \ln \left(x_{i}^{e}\left(p^{*}\right)\right) \frac{x_{i}^{e}\left(p^{*}\right)}{\alpha_{i} x_{i}^{c}+x_{i}^{e}\left(p^{*}\right)}$. Hence we indeed expect the estimate for conventional generation to be larger, as conventional capacity on average exceeds renewable capacity.
} 


\subsection{Robustness to cost estimates}

Our findings rely on engineering estimates for marginal production costs. To obtain cost estimates, we follow the large body of literature that models firm behavior and measures marginal costs and mark-ups in electricity markets (e.g., Wolfram, 1999; Borenstein et al., 2002; Mansur, 2007; Hortaçsu and Puller, 2008). In particular, we construct marginal costs by accounting for each plant's fuel type, fuel efficiency, and regulatory permit costs. As common, we assume that each plant has constant marginal cost up to its hourly operating capacity.

Wolak (2007) and Reguant (2014) show that this standard approach abstracts from ramping or start-up costs of power plants. These costs mainly arise from depreciation of the equipment when plants quickly increase or decrease generation, and would lead us to understate the costs and to overstate the mark-up. When this measurement bias is correlated to a firm's inframarginal renewable or conventional generation, our estimates in turn are biased.

To rule out such engineering-based explanations, we perform two robustness checks. The estimation results for both robustness checks are shown in Table A.1 in the Appendix. First, we exploit the Spanish market design that allows firms to submit complex bids to announce start-up and ramping costs. We therefore investigate a sub-sample that only includes plants for which firms did not submit complex bids and for which we presume the absence of startups costs. ${ }^{18}$ When re-running our regressions with this sample, the estimates for renewable and conventional capacity remain significant and robust in magnitude. Also the effect of the slope of residual demand remains robust.

Second, we restrict our analysis to plants that have submitted bids of zero (for their first of 25 possible bid steps per plant) in hour t and $t-1$. Thereby we restrict our sample to plants who have already been operating in the previous hour, and in addition seek to operate with certainty in hour t. Consequently, these plants should not face significant start-up or ramping costs from hour t-1 to hour t. We again confirm our main findings, as shown in Table A.1 in the Appendix.

While our results are in line with the underlying mechanism of the model, equation (7) implicitly predicts estimates of $1 \%$. Notably, when excluding complex bids we move closer to the magnitudes predicted by theory. That is, the estimates for inframarginal capacity move closer to 1 . We obtain even better fits with theory when excluding complex bids and

\footnotetext{
${ }^{18}$ To focus on sub-samples is a standard approach. For instance, to rule out engineering-based explanations for mark-ups, Hortaçsu and Puller (2008) consider early morning hours where flexible plants without ramping costs operate.
} 
only using mark-ups when firms indeed set the clearing price or submit very close bids to the clearing price. This indicates that complex costs and discrete bids to some degree explain deviations from our bidding model. ${ }^{19}$

\subsection{Effects for large producers}

Next, we explore the pricing behavior of the two largest generators, Endesa and Iberdrola, as they control the main share of renewable production. Both companies also own substantial conventional capacities. Endesa at times supplied more than 14,000 MW per hour of thermal generation and Iberdrola up to 12,000 MW. The picture reverses for renewable generation. Endesa sold up to $700 \mathrm{MW}$, while Iberdrola's sales reached more than 2,100 MW.

Figure 1 graphs each firm's hourly mark-up over its marketed renewable output in that hour. In line with our estimations, we plot the logarithmic scale, which shows that a loglinear relationship indeed represents the data well. For both firms, we plot selected hours, i.e., 12 noon (to $1 \mathrm{PM}$ ) and 4 PM (to 5 PM). The graphs are clearly indicating the positive relationship of mark-up and renewable output. Re-running our regressions for a sample that only contains the two largest firms again confirms our main results.

To illustrate the effects on supply curves and residual demand, Figure 2 plots the entire supply function for Iberdrola in two selected and exemplary hours. It comprises two plots with similar conventional production and the identical marginal power plant during the same hour of the day. The left panel, however, shows a selected hour at the end of 2004, where Iberdrola only sold about $100 \mathrm{MW}$ of renewable output via the premium mechanism, and received the tariff for the bulk of its clean output. In contrast, the right panel depicts the bid curve at a later point in our sample, where Iberdrola had migrated nearly all of its renewable output to the premium mechanism and, in that hour, sold about 1,700 MW of renewable generation in the market. The right panel clearly indicates higher residual demand. This is in line with the conjecture that every unit not sold via the tariff but instead in the market increases a firm's residual demand. Also the supply curve is much steeper in the right panel, where Iberdrola obtains the mark-up over a larger amount of inframarginal capacity. In combination with the outward shift in residual demand this leads to both, a larger mark-up and a higher clearing price.

\footnotetext{
${ }^{19}$ That mark-ups differ in magnitude from optimality conditions has also been found in previous literature. Wolfram (1999) finds mark-ups for the British market that were too low to result from profit maximizing firms, conjecturing that this was due to political pressure or unobserved quantities of forward contracts. Hortaçsu et al. (2019), taking forward contracts into account, also identify bids that are not profit-maximizing in the Texas power market, relating this to differences in the strategic ability of firms.
} 


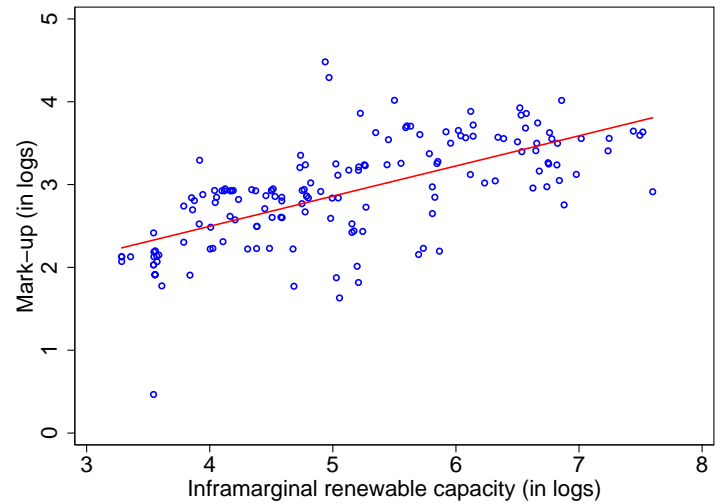

(a) Iberdrola, 12 noon

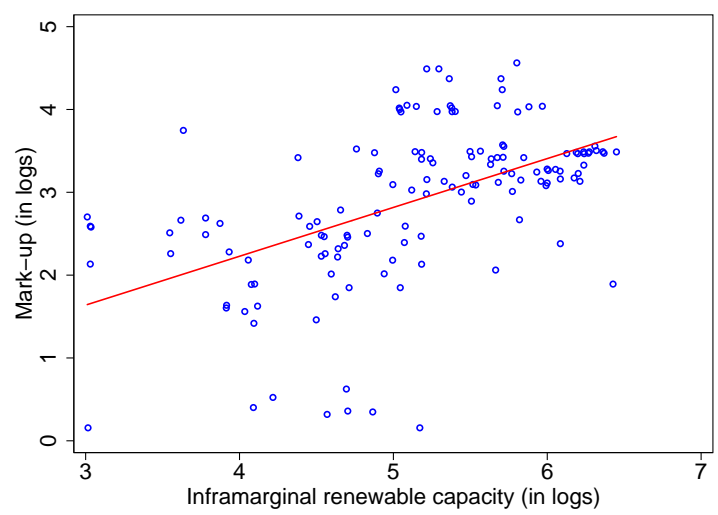

(c) Endesa, 12 noon

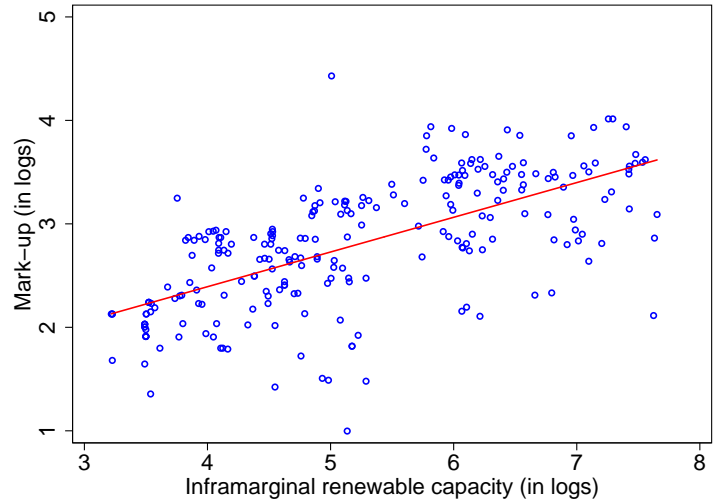

(b) Iberdrola, $4 \mathrm{PM}$

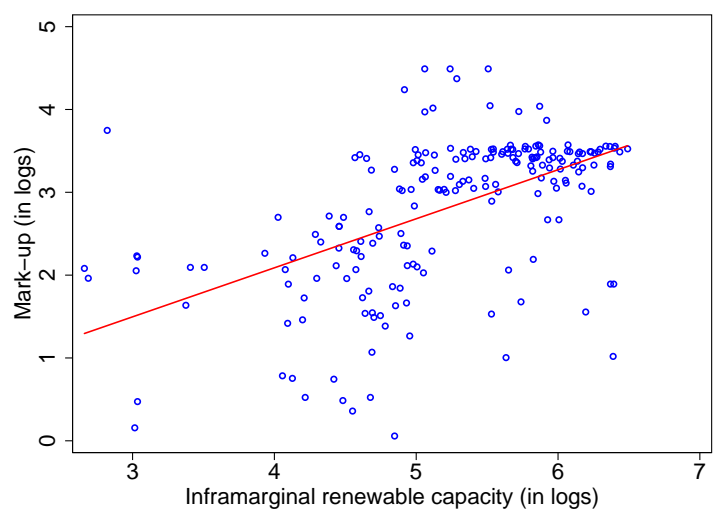

(d) Endesa, 4 PM

Figure 1: Mark-up (in logs) over inframarginal renewable output (in logs) for selected hours for Iberdrola and Endesa. The graph comprises all hours over the full sample from January 2004 to December 2005 with positive renewable output.

\subsection{Competing renewable output and evolution of market shares}

Last, we investigate the strategic effects of competing firms' renewable generation. In our model, the business-stealing effect of competing renewable output is captured in the residual demand left for firm $i$, which derives from the price distribution $H_{i}(p)$. Recall that this price distribution is modeled as a function of the uncertain aggregate renewable output of all rival firms. Hence the variation in aggregate renewable output can be employed to proxy the variation in $H_{i}(p)$. We therefore re-estimate our main specifications using the aggregate renewable output of competitors instead of the residual demand slope. Hence, we test in how far competing renewable output effects the ability of firm $i$ to exercise market power. As can 


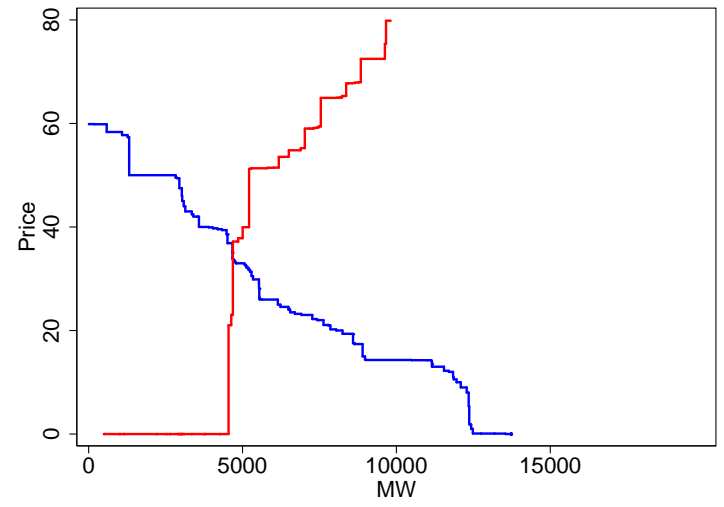

(a) Iberdrola on $12 / 28 / 20044$ PM

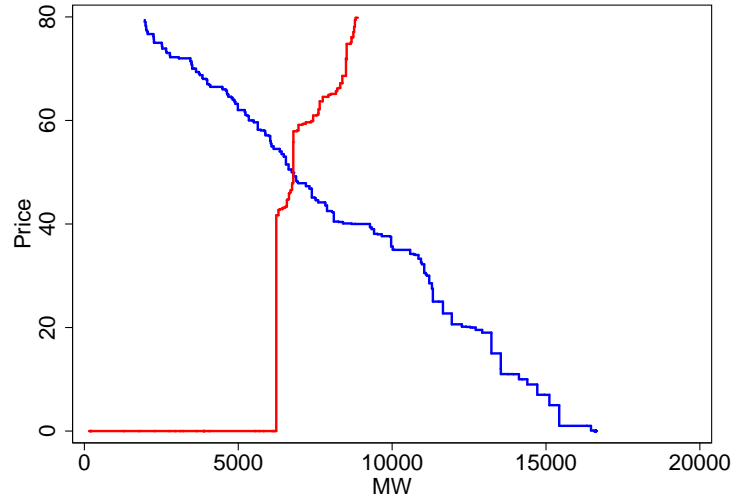

(b) Iberdrola on 11/10/2005 4 PM

Figure 2: Bid curves for Iberdrola with few marketed renewable output (left) and a high amount of renewable capacity (right). Both plots are showing bids and residual demand for $4 \mathrm{PM}$ and on a weekday. In the left graph, Iberdrola sells conventional output of 4,600 MW and renewable output of $100 \mathrm{MW}$. In the right graph, Iberdrola sells conventional output of 5,100 MW and renewable output of about 1,700 MW.

be seen in Table 3, our results are again robust for this case. The estimates on renewable and conventional capacity are in line with our previous results, both in terms of significance and magnitude. Further and as can be expected, the renewable output by other firms decreases mark-ups due to a business-stealing effect, whereas a firm's own sales increase its mark-up.

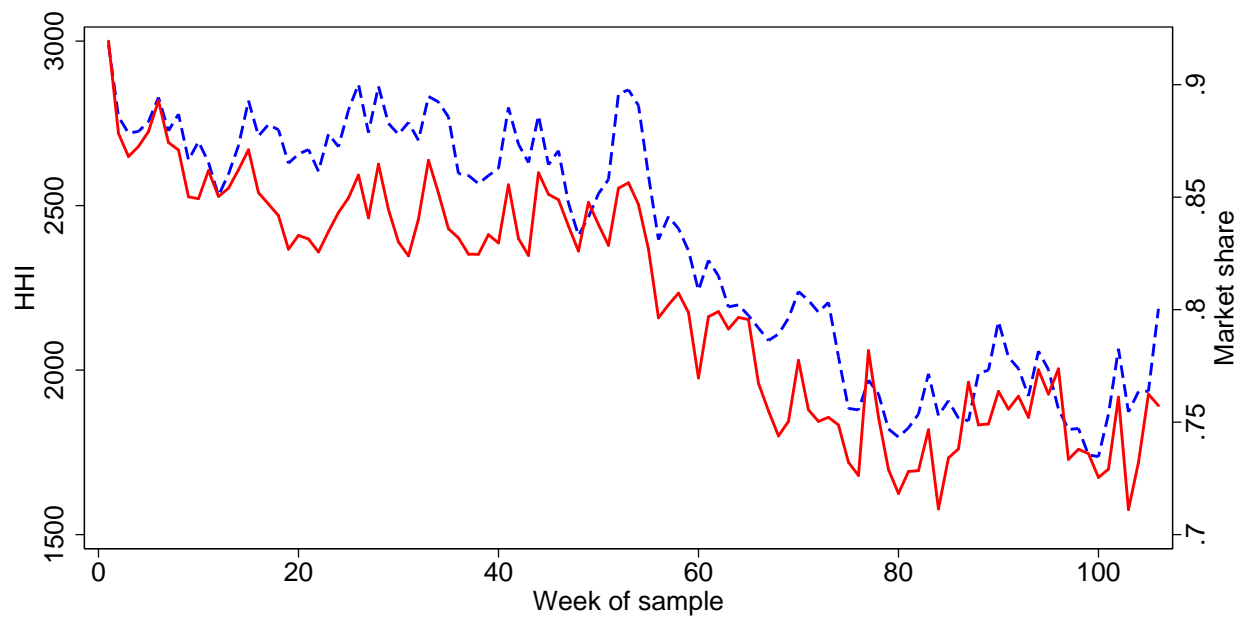

Figure 3: HHI (dashed line) and market share for the four largest firms (solid line).

Note that competing renewable output can either come from incumbent companies or from new, typically small, renewable producers. To further investigate market entry, Figure 
Table 3: Mark-up regressions controlling for competing renewable output.

\begin{tabular}{lcc}
\hline \hline & $(1)$ & $(2)$ \\
\hline $\begin{array}{l}\text { Renewable } \\
\ln \left(1+\theta_{i}\right)\end{array}$ & 1.768 & \\
& $(21.00)$ & \\
$\ln \alpha_{i} x_{i}^{c}$ & & 0.052 \\
& & $(18.05)$ \\
\hline Conventional & & \\
$\ln x_{i}^{e}\left(p^{*}\right)$ & 0.397 & 0.427 \\
& $(18.78)$ & $(19.90)$ \\
Competitors' renewables & & \\
& -0.346 & -0.350 \\
& $(-21.33)$ & $(-21.27)$ \\
\hline Observations & 30,387 & 30,387 \\
$\mathrm{R}^{2}$ & 0.70 & 0.70 \\
\hline \hline
\end{tabular}

Notes: Dependent variable is the mark-up by firm $i$ in auction $t$. Specification (1) uses a firm's share of renewable to conventional output, $\ln \left(1+\theta_{i}\right)$, as explanatory variable. Specification (2) uses a firm's amount of marketed renewable output, $\ln \alpha_{i} x_{i}^{c}$. Sample runs from January 2004 to December 2005. T-statistics are in parentheses. Standard errors are clustered at the auction-level. All regressions include plant, company, hour, weekday, month, and year fixed effects.

3 plots the evolution of the HHI and of the market share of the four largest firms. As can be seen, the large firms have lost market share during our period of observation, while they are still accounting for about $75 \%$ of the market at the end of our sample. The HHI shows a corresponding downward trend. Overall, the market remains fairly concentrated.

The declining market shares and HHI stress the impact of the subsidy mechanism. First, we rule out that price increases have been the result of a more concentrated market. In addition, our findings suggest that while technology policies to spur renewable energy can lead to market entry and change market structure, mark-ups and policy costs can increase and off-set potentially price-reducing effects of market entry. 


\section{Conclusion}

In this paper, we have studied how technology policy to support clean production influences competition and market structure in power markets. We have tailored our analysis to multiunit auctions, the dominant clearing mechanism in power markets around the globe. The model draws from canonical multi-unit auction frameworks and adds the effects of different mechanisms to support clean energy. We have applied our model to detailed bidding-level data from the Spanish power market, to a period of time when regulators re-organized the subsidy mechanism. The support mechanism changed from a fixed tariff to a price-dependent support, adding a premium on top of the equilibrium market price.

We have shown that fixed tariff mechanisms work equivalently to forward contracts and, in line with standard forward market models such as in Allaz and Vila (1993), decrease the market price set by strategic firms. When regulators change the support design to a mechanism based on a premium on top of the market price, this pro-competitive effect vanishes and prices ceteris paribus increase, as do policy costs. We also find that this effect is conditional on firms indeed having the ability to exercise market power. That is, our findings are conditional on imperfect spot market competition and illiquid forward markets that otherwise could attenuate observed effects.

In line with these model findings, our empirical estimates show that firms that sell large shares of subsidized clean energy to the market account for these in their pricing decisions and significantly increase their mark-up. At the same time, we have documented that the market concentration has fallen in parallel, as indicated by a decline in the HHI. Consequently, market concentration measures can be misleading when evaluating policies to promote clean energy in power markets.

Our findings highlight the role of mechanism design for technology support on market outcomes. Our findings also pertain to other forms of technology support, e.g., for quantity mechanisms such as procurement auctions for clean energy, where the choice of the auction design and the payment schemes should be considered in view of our findings. 


\section{References}

Acemoglu, Daron, Philippe Aghion, Leonardo Bursztyn, and David Hemous (2012) "The environment and directed technical change," American Economic Review, Vol. 102, pp. $131-66$.

Acemoglu, Daron, Ali Kakhbod, and Asuman Ozdaglar (2017) "Competition in Electricity Markets with Renewable Energy Sources.," Energy Journal, Vol. 38.

Adamou, Adamos, Sofronis Clerides, and Theodoros Zachariadis (2014) "Welfare implications of car feebates: A simulation analysis," The Economic Journal, Vol. 124, pp. F420-F443.

Aghion, Philippe, Antoine Dechezleprêtre, David Hemous, Ralf Martin, and John Van Reenen (2016) "Carbon taxes, path dependency, and directed technical change: Evidence from the auto industry," Journal of Political Economy, Vol. 124, pp. 1-51.

Allaz, Blaise and Jean-Luc Vila (1993) "Cournot competition, forward markets and efficiency," Journal of Economic Theory, Vol. 59, pp. 1-16.

Anderson, Edward and Pär Holmberg (2018) "Price instability in multi-unit auctions," Journal of Economic Theory, Vol. 175, pp. 318-341.

Batlle, Carlos, Ignacio J Pérez-Arriaga, and Patricio Zambrano-Barragán (2012) "Regulatory design for RES-E support mechanisms: Learning curves, market structure, and burdensharing," Energy Policy, Vol. 41, pp. 212-220.

Borenstein, Severin, James B Bushnell, and Frank A Wolak (2002) "Measuring market inefficiencies in California's restructured wholesale electricity market," American Economic Review, Vol. 92, pp. 1376-1405.

Bushnell, James B, Erin T Mansur, and Celeste Saravia (2008) "Vertical arrangements, market structure, and competition: An analysis of restructured US electricity markets," American Economic Review, Vol. 98, pp. 237-66.

Calel, Raphael and Antoine Dechezlepretre (2016) "Environmental policy and directed technological change: evidence from the European carbon market," Review of Economics and Statistics, Vol. 98, pp. 173-191. 
Crampes, Claude and Natalia Fabra (2005) "The Spanish electricity industry: plus ça change...," The Energy Journal, pp. 127-153.

Cullen, Joseph (2013) "Measuring the environmental benefits of wind-generated electricity," American Economic Journal: Economic Policy, Vol. 5, pp. 107-33.

Del Río, Pablo and Miguel A Gual (2007) "An integrated assessment of the feed-in tariff system in Spain," Energy Policy, Vol. 35, pp. 994-1012.

Doraszelski, Ulrich, Gregory Lewis, and Ariel Pakes (2018) "Just starting out: Learning and equilibrium in a new market," American Economic Review, Vol. 108, pp. 565-615.

Dressler, Luisa (2016) "Support schemes for renewable electricity in the European Union: Producer strategies and competition," Energy Economics, Vol. 60, pp. 186-196.

van Eijkel, Remco, Gerard H Kuper, and José L Moraga-González (2016) "Do firms sell forward for strategic reasons? An application to the wholesale market for natural gas," International Journal of Industrial Organization, Vol. 49, pp. 1-35.

European Commission (2006) "Integrated Pollution Prevention and Control Reference Document on Best Available Techniques for Large Combustion Plants."

Fabra, Natalia, Nils-Henrik von der Fehr, and David Harbord (2006) "Designing electricity auctions," The RAND Journal of Economics, Vol. 37, pp. 23-46.

Fabra, Natalia and Gerard Llobet (2019) "Auctions with Unknown Capacities: Understanding Competition among Renewables."

Fabra, Natalia and Mar Reguant (2014) "Pass-through of emissions costs in electricity markets," American Economic Review, Vol. 104, pp. 2872-99.

von der Fehr, Nils-Henrik and David Harbord (1993) "Spot Market Competition in the UK Electricity Industry," Economic Journal, Vol. 103, pp. 531-46.

von der Fehr, Nils-Henrik M and Stephanie Ropenus (2017) "Renewable energy policy instruments and market power," The Scandinavian Journal of Economics, Vol. 119, pp. $312-345$.

Goulder, Lawrence H, Ian WH Parry, Roberton C Williams Iii, and Dallas Burtraw (1999) "The cost-effectiveness of alternative instruments for environmental protection in a secondbest setting," Journal of Public Economics, Vol. 72, pp. 329-360. 
Gowrisankaran, Gautam, Stanley S Reynolds, and Mario Samano (2016) "Intermittency and the value of renewable energy," Journal of Political Economy, Vol. 124, pp. 1187-1234.

Green, Richard J and David M Newbery (1992) "Competition in the British electricity spot market," Journal of Political Economy, Vol. 100, pp. 929-953.

Gulati, Sumeet, Carol McAusland, and James M Sallee (2017) "Tax incidence with endogenous quality and costly bargaining: Theory and evidence from hybrid vehicle subsidies," Journal of Public Economics, Vol. 155, pp. 93-107.

Holmberg, Pär and David Newbery (2010) "The supply function equilibrium and its policy implications for wholesale electricity auctions," Utilities Policy, Vol. 18, pp. 209-226.

Holmberg, Pär, David Newbery, and Daniel Ralph (2013) "Supply function equilibria: Step functions and continuous representations," Journal of Economic Theory, Vol. 148, pp. $1509-1551$.

Hortaçsu, Ali, Fernando Luco, Steven L Puller, and Dongni Zhu (2019) "Does Strategic Ability Affect Efficiency? Evidence from Electricity Markets."

Hortaçsu, Ali and Steven L Puller (2008) "Understanding strategic bidding in multi-unit auctions: a case study of the Texas electricity spot market," The RAND Journal of Economics, Vol. 39, pp. 86-114.

Huse, Cristian and Claudio Lucinda (2013) "The market impact and the cost of environmental policy: evidence from the Swedish green car rebate," The Economic Journal, Vol. 124, pp. F393-F419.

IEA (2010) "Power generation from coal: measuring and reporting efficiency performance and CO2 emissions," CIAB International Energy Agency, Paris, Report: OECD/IEA2010, pp. 1-114.

IEA, OECD, NEA (2015) "Projected Costs of Generating Electricity 2015," International Energy Agency, Paris.

Ito, Koichiro and Mar Reguant (2016) "Sequential markets, market power, and arbitrage," American Economic Review, Vol. 106, pp. 1921-57. 
Johnstone, Nick, Ivan Haščič, and David Popp (2010) "Renewable energy policies and technological innovation: evidence based on patent counts," Environmental and Resource Economics, Vol. 45, pp. 133-155.

Kastl, Jakub (2006) "Discrete bids and empirical inference in divisible good auctions," Review of Economic Studies.

(2012) "On the properties of equilibria in private value divisible good auctions with constrained bidding," Journal of Mathematical Economics, Vol. 48, pp. 339-352.

Klemperer, Paul D and Margaret A Meyer (1989) "Supply function equilibria in oligopoly under uncertainty," Econometrica: Journal of the Econometric Society, pp. 1243-1277.

Mansur, Erin T (2007) "Upstream competition and vertical integration in electricity markets," The Journal of Law and Economics, Vol. 50, pp. 125-156.

Murdock, Hannah E, Rana Adib, Christine Lins, Flavia Guerra, Archita Misra, Louise Vickery, Ute Collier, Pharoah Le Feuvre, Emanuele Bianco, Simon Mueller et al. (2018) "Renewable Energy Policies in a Time of Transition."

Reguant, Mar (2014) "Complementary bidding mechanisms and startup costs in electricity markets," The Review of Economic Studies, Vol. 81, pp. 1708-1742.

_ (2019) "The Efficiency and Sectoral Distributional Impacts of Large-Scale Renewable Energy Policies," Journal of the Association of Environmental and Resource Economists, Vol. 6, pp. S129-S168.

del Río González, Pablo (2008) "Ten years of renewable electricity policies in Spain: An analysis of successive feed-in tariff reforms," Energy Policy, Vol. 36, pp. 2917-2929.

Schwenen, Sebastian (2015) "Strategic bidding in multi-unit auctions with capacity constrained bidders: the New York capacity market," The RAND Journal of Economics, Vol. 46, pp. $730-750$.

Taylor, Peter, Olivier Lavagne d'Ortigue, Nathalie Trudeau, and Michel Francoeur (2008) "Energy Efficiency Indicators for Public Electricity Production from Fossil Fuels IEA Information paper In Support of the G8 Plan of Action." 
Van Koten, Silvester and Andreas Ortmann (2013) "Structural versus behavioral remedies in the deregulation of electricity markets: An experimental investigation motivated by policy concerns," European Economic Review, Vol. 64, pp. 256-265.

Vázquez, Carlos, Carlos Batlle, M Rivier, and JI Pérez-Arriaga (2006) "Regulated tariff design in a liberalized power system: the case of Spain," in IIT Working Paper IIT06-0XX: Instituto de Investigación Tecnológica, Universidad Pontificia Comillas.

Wilson, Robert (1979) "Auctions of shares," The Quarterly Journal of Economics, pp. 675689.

Wolak, Frank A (2000) "An empirical analysis of the impact of hedge contracts on bidding behavior in a competitive electricity market," International Economic Journal, Vol. 14, pp. 1-39.

- (2003a) "Identification and Estimation of Cost Functions Using Observed Bid Data," in Advances in Economics and Econometrics: Theory and Applications, Eighth World Congress, Vol. 2, p. 133, Cambridge University Press.

Wolak, Frank A. (2003b) "Measuring unilateral market power in wholesale electricity markets: the California market, 1998-2000," American Economic Review, Vol. 93, pp. 425-430.

Wolak, Frank A (2007) "Quantifying the supply-side benefits from forward contracting in wholesale electricity markets," Journal of Applied Econometrics, Vol. 22, pp. 1179-1209.

Wolfram, Catherine D (1998) "Strategic bidding in a multiunit auction: an empirical analysis of bids to supply electricity in England and Wales," The RAND Journal of Economics, pp. 703-725.

- (1999) "Measuring duopoly power in the British electricity spot market," American Economic Review, Vol. 89, pp. 805-826. 


\section{Appendix}

\section{A Equilibrium supply functions}

Simplifying equation (3) by writing expected profits as $\mathbb{E}\left[\pi_{i}\right]=\int_{\underline{p}}^{\bar{p}} \pi\left(S_{i}(p)\right) H_{p}(p, S(p)) d p$, we can integrate by parts and obtain

$$
\mathbb{E}\left[\pi_{i}\right]=\left.\pi\left(S_{i}(p)\right) H(p)\right|_{\underline{p}} ^{\bar{p}}-\int_{\underline{p}}^{\bar{p}}\left[\frac{d}{d p} \pi\left(S_{i}(p)\right)\right] H(p) d p
$$

Using $H(\underline{p})=0$ and $H(\bar{p})=1$ yields

$$
\mathbb{E}\left[\pi_{i}\right]=\pi\left(S_{i}(\bar{p})\right)-\int_{\underline{p}}^{\bar{p}}\left[\frac{d}{d p} \pi\left(S_{i}(p)\right)\right] H(p) d p .
$$

The first term is a constant, so maximizing the integrand of the second term suffices. The derivation then proceeds as in Hortaçsu and Puller (2008), where renewable energy support in our model replaces the effect of forward contracts.

To derive the cumulative price distribution $H_{i}(\cdot)$, let the index $-i$ denote aggregate market quantities net of firm $i$. Then, the probability that the clearing price $p^{*}$ is below any price $p$ can be written as the probability that supply is larger than demand at price $p$ :

$$
\begin{aligned}
H_{i}\left(p, S_{i}\right) & =\operatorname{Pr}\left(S_{-i}\left(p, x_{-i}^{c}\right)+\varepsilon_{-i}\left(x_{-i}^{c}\right)+S_{i}>D(p) \mid S_{i}\right) \\
& =\operatorname{Pr}\left(\varepsilon_{-i}\left(x_{-i}^{c}\right)>D(p)-S_{-i}(p)-S_{i} \mid \hat{S}_{i}\right) \\
& =1-F_{i}\left(D(p)-S_{-i}(p)-S_{i} \mid S_{i}\right)
\end{aligned}
$$

where $F_{i}$ is the cumulative distribution function of $\varepsilon_{-i}$. The derivatives are

$$
H_{S}=\frac{\partial H_{i}}{\partial S_{i}}=-f_{i}\left(D(p)-S_{-i}(p)-S_{i}\right) \frac{\partial}{\partial S_{i}}\left(D(p)-S_{-i}(p)-S_{i}\right)
$$

and

$$
H_{p}=\frac{\partial H_{i}}{\partial p}=-f_{i}\left(D(p)-S_{-i}(p)-S_{i}\right) \frac{\partial}{\partial p}\left(D(p)-S_{-i}(p)-S_{i}\right) .
$$

Hence we can write

$$
\frac{H_{S}\left(p, S^{*}(p)\right)}{H_{p}\left(p, S^{*}(p)\right)}=\frac{1}{m_{i}(p)}
$$

with $m_{i}(p)=-\frac{\partial}{\partial p}\left(D(p)-S_{-i}(p)\right)$ being the slope of firm $i$ 's residual demand. Because the slope of residual demand, $\frac{\partial}{\partial p}\left(D(p)-S_{-i}(p)\right)$ is negative, $m_{i}$ is positive and measures the steepness of the residual demand curve. 


\section{B Data}

This appendix provides additional details on our data. To obtain our final sample, we proceed as follows. We first combine the bidding data with power plant lists provided by the market operator (OMIE). The bidding data, i.e. supply and demand curves, are available on the website of the market operator (labeled curva_pbc_uof). Additionally, we use data on aggregate hourly production (labeled pdbc_stot and pdbc_stota) to derive aggregate renewable production supported via the premium and the tariff mechanism, respectively.

We in addition match our sample with information from Electra (Registro de productores de energía eléctrica). Electra publishes data sets on generation capacity in Spain. We also use open power system data that provides information for energy market modeling, including extensive information on European power plants. In combination with the power plant lists provided by OMIE, this matching allows us to extend our sample with the owner of the power plant, the production technology used, and the respective year of commissioning of the plant.

To obtain marginal costs, we use commodity price data from Bloomberg (hard coal and fuel oil) and Thomson Reuters (natural gas). We add EU ETS Phase I prices from Bloomberg. Hard coal prices refer to Australian steam coal (Bloomberg id CLSPAUNE), freight on board in Newcastle with a calorific value of $6000 \mathrm{kc}$ and are updated on a weekly basis. Fuel oil prices reflect daily CIF prices for Milazzo (Italy) with a sulfur content of one percent (Bloomberg id N6M1.OCC).

For natural gas we use Dutch TTF (Title Transfer Facility) prices (Thomson Reuters identifier TRNLTTD) provided on a daily basis. Within our sample, the largest share of natural gas imports stem from Algeria, for which no granular price series exists. We compared available price points for Algerian import prices with the high resolution TTF data we received from Bloomberg, confirming that TTF price data is a good approximation. Furthermore, the TTF price data is in line with the Gazexport-Ruhrgas prices applied by Fabra and Reguant (2014) for the same period.

There was no detailed price data available for lignite as input factor. For our calculations we used a fixed price of $8 € /$ ton, based on engineering studies. However, we conjecture lignite prices to be rather stable over time.

Power plant efficiency is estimated using the commissioning date as proxy. Based on engineering reports (European Commission, 2006; Taylor et al., 2008; IEA, 2010), we attach fuel efficiency to each power plant conditional on the year of commissioning. Combining commodity price data, cost of carbon, power plant efficiency and heating values of the respective fuels, we estimate marginal production cost. We ignore additional marginal cost factors, such as O\&M cost in our estimation. According to (IEA, 2015), median levels of variable O\&M cost accrue to $2.70 \mathrm{USD} / \mathrm{MWh}$ for CCGT and to $3.40 \mathrm{USD} / \mathrm{MWh}$ for coal power production, respectively. We assume variable O\&M cost to be constant over time. We could not identify reasons for significant changes in O\&M cost during our period of observation. 
To determine hourly residual demand curves for each market participant in our sample, we again make use of the supply and demand curves provided by the market operator. To derive residual demand for company $i$, we first calculate the aggregate supply of all competing market participants $j \neq i$, as well as aggregate demand. Subtracting aggregate supply of all firms $j$ from aggregate demand, we isolate residual demand for firm $i$. Last, we measure the slope of the residual demand curve at the marginal bid submitted by firm $i$, making use of the smooth.spline function in $\mathrm{R}$.

\section{Tables and figures}

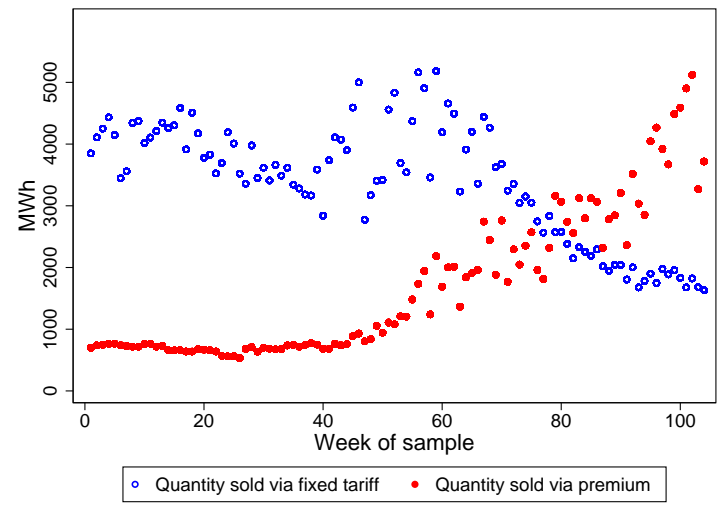

(a)

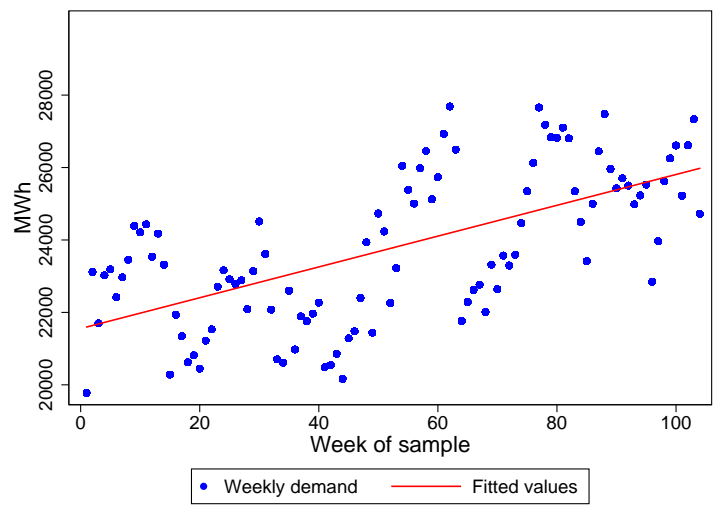

(b)

Figure A.1: Panel (a) plots the evolution of the weekly average renewable generation in the tariff mechanism and in the premium mechanism. Panel (b) plots the weekly average market sales on the day-ahead market, along with conditional means for each week of the sample. As can be seen, the demand in the market from the beginning of our sample to the end of our sample increases by a comparable quantity that leaves the tariff mechanism and is then sold under the premium mechanism in the day-ahead market. 
Table A.1: Mark-up regressions conditional on the use of complex bids.

\begin{tabular}{|c|c|c|c|c|}
\hline & (1) & $(2)$ & $(3)$ & $(4)$ \\
\hline $\begin{array}{r}\text { Renewable } \\
\ln \left(1+\theta_{i}\right)\end{array}$ & $\begin{array}{l}1.033 \\
(8.79)\end{array}$ & $\begin{array}{c}1.415 \\
(13.40)\end{array}$ & & \\
\hline $\ln \alpha_{i} x_{i}^{c}$ & & & $\begin{array}{c}0.037 \\
(12.20)\end{array}$ & $\begin{array}{c}0.042 \\
(13.10)\end{array}$ \\
\hline $\begin{array}{l}\text { Conventional } \\
\ln x_{i}^{e}\left(p^{*}\right)\end{array}$ & $\begin{array}{c}0.644 \\
(25.84)\end{array}$ & $\begin{array}{c}0.672 \\
(25.52)\end{array}$ & $\begin{array}{c}0.679 \\
(26.84)\end{array}$ & $\begin{array}{c}0.694 \\
(26.02)\end{array}$ \\
\hline $\begin{array}{l}\text { Demand slope } \\
\ln m^{*}\end{array}$ & $\begin{array}{c}-0.044 \\
(-11.39)\end{array}$ & $\begin{array}{c}-0.049 \\
(-12.31)\end{array}$ & $\begin{array}{c}-0.045 \\
(-11.73)\end{array}$ & $\begin{array}{c}-0.052 \\
(-13.05)\end{array}$ \\
\hline $\begin{array}{l}\text { Own retail demand } \\
\ln \text { (retail demand over total) }\end{array}$ & $\begin{array}{l}-0.599 \\
(-18.57)\end{array}$ & $\begin{array}{l}-0.583 \\
(-16.86)\end{array}$ & $\begin{array}{l}-0.605 \\
(-18.84)\end{array}$ & $\begin{array}{c}-0.583 \\
(-16.98)\end{array}$ \\
\hline Plant fixed effects & Yes & Yes & Yes & Yes \\
\hline Company fixed effects & Yes & Yes & Yes & Yes \\
\hline Observations & 22,948 & 21,863 & 22,948 & 21,863 \\
\hline $\mathrm{R}^{2}$ & 0.72 & 0.72 & 0.72 & 0.72 \\
\hline
\end{tabular}

Notes: Dependant variable is the mark-up by firm $i$ in auction $t$. Specifications (1) and (2) use a firm's share of renewable to conventional output, $\ln \left(1+\theta_{i}\right)$, as explanatory variable. Specifications (3) and (4) use a firm's amount of marketed renewable output, $\ln \alpha_{i} x_{i}^{c}$. Sample runs from January 2004 to December 2005. Specifications (1) and (3) use plants that have not submitted complex bids. Specifications (2) and (4) use plants that were operating already in the previous hour. T-statistics are in parentheses. Standard errors are clustered at the auction-level. All regressions include hour, weekday, month, and year fixed effects. 